\title{
XXVII.
}

\section{Eleidin in Carcinomperlor.}

\section{Von Dr. Julius Steinhaus aus Warschan.}

In seiner Berichtigung, das Vorkommen von Eleidin in Epidermoidzellen betreffend" (dies. Areh. Bd. 128. Heft 2), hebt Herr Dr. F. Franke hervor, dass Dr. Schuchardt (Volkm. Vortr. No. 257. S. 2226) in Schichtungskugeln einer Verruca cancrosa einmal Eleidin beobacbtet hat, dass also meine Behauptung, wonach in den Carcinomperlen die Bildung von Eleidinkörnehen als Intermediärstadium bei der Verhornung fehlen soll (dies. Arch. Bd. 127. S. 178), unrichtig sei.

Ich kann nur IIerm Franke für den Hinweis auf Dr. Schuchardt's Arbeit, die mir unbekannt war, danken, bemerke dabei zugleich noch, dass ich seitdem selbst bei der Verhornung in Carcinomperlen Eleidin beobachtet habe, woriber ich bald des Näheren zu berichten gedenke. 